\title{
CARLOS JANSEN E A VULGARIZAÇÃO LITERÁRIA PARA A MOCIDADE
}

\author{
Lia Araujo Miranda de Lima* \\ Universidade de Brasília
}

\author{
Germana P. H. de Sousa** \\ Universidade de Brasília
}

\begin{abstract}
Resumo: Neste artigo estudamos as traduções de Carlos Jansen para a mocidade - faixa etária que corresponde aproximadamente aos conceitos contemporâneos de pré-adolescência e adolescência -, realizadas em fins do século XIX. Jansen foi pioneiro ao traduzir, em português brasileiro, obras para a juventude, entre as quais romances de Swift, Defoe e Cervantes. Suas versões, amplamente adaptadas, tinham finalidade pedagógica,
\end{abstract}

\footnotetext{
* Mestre em Estudos da Tradução pela Universidade de Brasília (2015). Graduada em Letras-Tradução pela Universidade de Brasília (2008), com habilitação em Francês, e em Comunicação Social pela Universidade Federal de Minas Gerais (2004), com habilitação em jornalismo. Brasília, Distrito Federal, Brasil. Email: liaamiranda@gmail.com

** Possui diploma de Licence en Portugais - Université de Rennes 2 - Haute Bretagne (1987), de Licence en Français Lettres Modernes - Université de Rennes 2 - Haute Bretagne (1988), Maitrise en Lettres Modernes - Université de Rennes 2 - Haute Bretagne (1989), Mestrado em Literatura pela Universidade de Brasília (1998) e Doutorado em Teoria Literária pela Universidade de Brasília (2004). Bolsista de PDE/CNPq - Pós Doutorado na Université de Rennes 2 - Haute Bretagne em Estudos da Tradução (2006-2007) e Pós-Doutorado na Pós-Graduação em Estudos da Tradução - PGET/UFSC e Université de Montréal UdeM/ Canadá (2013). Atualmente é Professora Adjunto IV da Universidade de Brasília, Departamento de Línguas Estrangeiras e Tradução. Brasília, Distrito Federal, Brasil. E-mail:germanahp@gmail.com
} 
servindo como material de leitura para crianças e jovens que frequentavam as escolas - daí ter sido qualificado por críticos da época como vulgarizador. A pesquisa compreendeu a análise de periódicos publicados entre 1880 e 1899, disponíveis na Hemeroteca Digital Brasileira, da Biblioteca Nacional, que fornecem dados sobre a divulgação e a recepção de suas obras. Propomos enriquecer as pesquisas históricas sobre a literatura infantil e juvenil no Brasil e avaliar em que medida o projeto pedagógico de Jansen regeu suas práticas tradutórias.

Palavras-chave: Carlos Jansen. Tradução. Adaptação. História. Literatura infantil e juvenil.

\title{
CARLOS JANSEN AND THE LITERARY VULGARIZATION FOR THE YOUTH
}

\begin{abstract}
In this article we study the translations of Carlos Jansen for the youth, age group corresponding approximately to the contemporary concepts of preadolescence and adolescence, made at the end of the 19th century. Jansen was a pioneer in translating into Brazilian Portuguese works for the youth among which novels by Swift, Defoe, and Cervantes. His widely adapted versions had a pedagogical goal, serving as a reading material for children and adolescents attending schools. For this reason he was called a "vulgarizer" by critics of that period. The research encompassed the analysis of newspapers published between 1880 and 1899, available at the National Library's Hemeroteca Digital Brasileira, which provide data on the advertising and reception of his works. We intend to enrich historical research on children's literature in Brazil and analyse to what degree Jansen's pedagogical project has governed his translation practice.
\end{abstract}

Keywords: Carlos Jansen. Translation. Adaptation. History. Children's and young adult literature.

Os estudos históricos sobre literatura infantil brasileira nunca deixam de citar o pioneirismo do professor teuto-brasileiro Carlos Jansen, "não só pelas traduções que realizou, como também pela consciência que tinha do problema" (ARROYO, 1990, p. 172). O problema, no caso, era a ausência de textos em português brasileiro para a leitura das crianças e jovens que começavam a povoar as escolas no final do século XIX, e as "manifestas inconveniências re- 
presentadas pelas traduções ou originais portugueses" (ARROYO, 1990, p. 172). Malgrado seu reconhecido pioneirismo, trabalhos sobre Jansen enquanto tradutor de literatura infanto-juvenil são relativamente escassos nas pesquisas acadêmicas, aparecendo quase sempre à margem de Monteiro Lobato em estudos comparativos sobre adaptações para jovens leitores.

Carlos Jansen (182911889) foi professor de alemão no Colégio Pedro II, no Rio de Janeiro. Natural de Colônia, instalou-se no Rio Grande do Sul em 1851, onde integrou-se à vida pública exercendo atividades jornalísticas, literárias e políticas (HOHLFELDT, 2003, p. 68). Os principais levantamentos biográficos sobre Jansen econtram-se em livros dedicados à sua atuação enquanto escritor de romances de folhetim e representante de língua alemã na imprensa gaúcha ${ }^{2}$, poucos dados se achando a seu respeito em obras dedicadas à história da literatura infantil.

No Rio de Janeiro, Jansen participou d'A Liga do Ensino no Brasil, associação que se propunha a fundar uma escola modelo (DIÁRIO DE BELÉM, 22/11/1883, ano XVI, n. 355, p. 3) $)^{3}$. Entre seus 50 membros fundadores estavam Rui Barbosa, Hilário Ribeiro, Franklin Távora, Sousa Bandeira, Capistrano de Abreu, Ferreira de Araujo, Sílvio Romero e Machado de Assis, alguns dos quais alunos de alemão de Jansen (MONTELLO, 1967, p. 16). Os três últimos, além de Barbosa, foram prefaciadores de suas traduções.

Enquanto tradutor, Jansen fez poucas incursões na literatura adulta, entre as quais identificamos as versões para o alemão dos poemas $O$ Imperador e Partida e Regresso, do Barão de Paranapiacaba, publicados pela Imprensa Nacional ${ }^{4}$. Trabalhou especialmente com literatura para a mocidade e material pedagógico, incluindo cartilhas de ensino de língua estrangeira - francês e alemão - e os opúsculos científicos, seu trabalho mais extenso no campo da tradução. O Catálogo n. 5 da Livraria Universal da Laemmert - Contos morais, educação primária arrola 7 volumes: Geografia física e Geologia, por A. Geikie; Astronomia, por N. Lockier; Química, por H.P. Roscoe; Física, por Balfourt Stewart; Botânica, por A. du Bary; Zoologia, por O. Schmidt ${ }^{5}$. 
Franklin Távora (1880) em artigo publicado na Revista Brasileira acerca dos três primeiros opúsculos, explica que consistiam em "resumidos tratados" empreendidos por professores das universidade de Edimburgo, Manchester e Strasburgo, adaptados do inglês ao português para uso das escolas primárias. Távora exalta os méritos da empreitada de Jansen, afirmando que o professor não fez "uma simples tradução", mas "apropriou as lições dos mestres europeus aos usos dos discípulos brasileiros, à nossa terra" .

Gama Rosa assinou, na Gazeta da Tarde de 1882, artigo onde afirmava que a substituição do material pedagógico das escolas, reputado como obscurantista e ultrapassado, pelos opúsculos científicos de Jansen fora "o grande acontecimento destes últimos tempos":

\begin{abstract}
Bem aplicados, os opúsculos científicos do Sr. Carlos Jansen serão suficientes para realizar a frase de Goethe, para operar a grande revolução; eles darão inexoravelmente por terra com a Cartilha, o Tesouro de meninos, o Catecismo, o Iris clássico, o padre Manoel Bernardes e todas as velharias que obstruem o ensino. (ROSA, 1882, p.2).
\end{abstract}

Rosa se refere a Jansen como "ilustre vulgarizador", conferindo uma conotação positiva e progressista à tarefa de tornar o conhecimento científico acessível aos jovens, conforme tendência dos "sábios europeus".

Após a publicação dos opúculos, Jansen voltou suas atenções para a literatura, propondo-se a criar "entre nós uma biblioteca juvenil para ensinar a ler a geração presente" (BARBOSA, 1955, p. 249-250). Araripe Júnior exalta a iniciativa de Jansen, denunciando a carência de material para a educação estética das crianças e a pobreza literária do que havia disponível até então:

Muitos pedagogos no Brasil se têm preocupado com a educação moral, com a educação intelectiva, com a educação 
física das crianças. Nenhum, porém, ainda dera à parte da educação referente à estética todo o desenvolvimento de que é esta suscetível. [...]

Pois bem, o Sr. Carlos Jansen [...] começou a publicar uma série de obras de imaginação, cujo fim principal é arrancar os espíritos infantis às perniciosas histórias de lobisomens da negra velha e a esterilidade das impressões do ambiente comum, para familiarizá-los com os monumentos mais compreensíveis e acessíveis das grandes literaturas. (JUNIOR, 1888, p. 74).

A bilioteca juvenil de Jansen compunha-se das seguintes obras:

\begin{tabular}{|l|l|l|}
\hline Data & Títulos & Prefácio \\
\hline 1882 & Contos seletos das mil e uma noites & Machado de Assis \\
\hline 1885 & Robinson Crusoe & Sílvio Romero \\
\hline $1886^{6}$ & D. Quixote de La Mancha & Ferreira de Araujo \\
\hline 1888 & $\begin{array}{l}\text { As viagens de Gulliver a terras } \\
\text { desconhecidas }\end{array}$ & Rui Barbosa \\
\hline 1891 & $\begin{array}{l}\text { Aventuras pasmosas do celebérrimo } \\
\text { Barão de Münchhausen }\end{array}$ & - \\
\hline
\end{tabular}

Arroyo (1990, p. 175) aponta, ainda, Contos para filhos e netos (1894), "outro livrinho de sua autoria de que nos faltam mais pormenores”. Lajolo e Zilberman (2007, p. 27) arrolam esta obra como tradução de Jansen, não como obra autoral, o que ilustra a dificuldade de se classificar as adaptações feitas naquele período. Hohlfeldt (2003, p. 71) menciona ainda a Seleção literária de autores alemães para jovens leitores, organizada em 1888 para servir de exercício de tradução. A Gazeta de Notícias traz maiores informações sobre a seleta: 
Como diz bem o próprio autor, na sua advertência, "por escassez no mercado de obras alemãs, ainda figura no programa do imperial colégio D. Pedro II o Jovem Teófilo, conto do cônego Schmidt, destinado a fazer as delícias das crianças de 8 a 10 anos!"

Nestas condições, oferecer à mocidade uma seleta em que figuram escritos de Lessing, Goethe e Schiller, os maiores vultos literários da Alemanha, é prestar relevantíssmo serviço à instrução pública. (08/11/1888, ano XIV, n. 312, capa). ${ }^{7}$

Naquele fim de século, produziam-se livros para crianças a partir de 3 anos de idade. Em publicidade da Laemmert na Gazeta da Tarde de 18/12/1897, separavam-se os livros em duas faixas etárias: infância, de 3 a 7 anos; e mocidade, de 8 a 14 anos (ano XVIII, n. 160 , p. 8$)^{8}$. Para o primeiro grupo, entre outros, anunciavam-se João Felpudo, Menino Verde e Animais falantes, do Dr. Heinrich Hoffmann, Robinson Crusoe (resumido por Marcos Valente), Contos para filhos e netos, de Carlos Jansen, além de contos morais, obras de ensino religioso e orações diárias. Para a mocidade, a Laemmert anunciava os cinco livros da biblioteca juvenil de Jansen. Dezessete anos após a publicação de As mil e uma noites, suas traduções ainda eram os únicos livros de literatura da lista, sendo os restantes obras pedagógicas e de ensino moral e religioso. As traduções empreendidas por Jansen ocuparam, assim, uma importante lacuna na oferta de material de leitura para crianças e adolescentes.

Os cinco volumes de sua biblioteca foram publicados pela Laemmert em edições de boa qualidade gráfica, tanto pelas ilustrações coloridas como pela encadernação. Das primeiras edições, ainda que raras, podem ser localizadas com alguma facilidade imagens digitalizadas das capas, folhas de rosto e páginas de ilustrações. Testemunham ainda sobre seu acabamento editorial os anúncios publicados nos periódicos que circularam no país nas duas últimas décadas do século XIX. 
Acerca das Mil e uma noites, o redator escreve que "a impressão é das mais nítidas que temos visto e a encadernação da obra, primorosa" (Gazeta de Notícias, 24/12/1882, ano VIII, n. 357, capa) ${ }^{9}$. A mesma Gazeta descreve a edição de Robinson Crusoe como "nitidamente impressa", numa "edição de luxo, adornada com esplêndidos cromos e magnífica capa ilustrada" (26/02/1885, ano XI, n. $57)^{10}$. O editor anunciava ainda uma edição especial, a um preço mais elevado, com "encadernação em percalina inglesa com folhas douradas" (Gazeta de Notícias, 06/03/1885, ano XI, n. 65, p. 4) ${ }^{11}$.

Chama atenção a prevalência do nome do adaptador sobre o do autor das obras. A edição de Robinson Crusoe, por exemplo, traz o nome de Defoe apenas no prefácio de Romero (FARIA, 2008, p. 40). O que hoje se designa obra adaptada era então nomeado obra redigida (para determinado público), colocando o tradutor-redator no patamar de autor.

Os anúncios da Laemmert trazem ainda informações sobre os procedimentos adaptativos empregados por Jansen. Acerca das Mil e uma noites, encontramos a seguinte descrição na Gazeta de Notícias:

Destinado este livro para distração amena nos seios das famílias, foi eliminado com cuidado tudo quanto pudesse ofender o decoro, sem que entretanto ficasse prejudicado o texto no tesouro de imaginação que tanto o recomenda. A apreciação de um dos mais eminentes escritores, que serve de prefácio à obra, confirma o nosso juízo favorável [...]. $\left(26 / 12 / 1886\right.$, ano XII, n. 360 , p. 4). ${ }^{12}$

O Diário do Brasil de 27/12/1882 relata que Jansen selecionou entre os contos "os mais interessantes" e os fez preceder de prefácio do "mimoso escritor Machado de Assis", reunindo-os num livro "útil para a adolescência" (ano II, n. 293, p. 2) ${ }^{13}$. Além de selecionar episódios das histórias, excluindo outros, Jansen condensava a narrativa, cortava frases, reescrevia-as em ordem direta e substituía o uso da primeira pela terceira pessoa, o "que facilita 
a compreensão da criança, que capta melhor a narrativa contada por outra pessoa e não pelo próprio protagonista" (FARIA, 2008).

Os prefácios das obras traduzidas por Jansen, cujos célebres autores eram constantemente mencionados nos anúncios da Laemmert, mereceriam um estudo a parte. Dentro do escopo deste artigo, buscamos tecer alguns comentários sobre cada um deles e discorrer sobre a polêmica gerada pelo prefácio de Ferreira de Araujo ao Dom Quixote.

Carlos Jansen convidou grandes personalidades literárias para prefaciar suas quatro traduções literárias publicadas em vida e, assim, legitimá-las diante do público. O mais antigo desses prefácios é o de Machado de Assis às Mil e Uma Noites, breve texto com elogios ao caráter universal e atemporal da coletânea árabe e ao trabalho de Jansen:

O Sr. Carlos Jansen tomou a si dar à mocidade brasileira uma escolha daqueles famosos contos árabes das Mil e Uma Noites, adotando o plano do educacionista alemão Franz Hoffmann. Esta escolha é conveniente; a mocidade terá assim uma amostra interessante e apurada das fantasias daquele livro, alguns dos seus melhores contos, que estão aqui, não como nas noites de Sheherazade, ligados por uma fábula própria do Oriente, mas em forma de um repositório de coisas alegres e sãs. (ASSIS, 1994, s/p). ${ }^{14}$

O prefácio de Sílvio Romero ao Robinson Crusoe é mais difícil de ser acessado, pois as edições traduzidas por Jansen tornaram-se obras raras. Segundo periódico da época, trata-se de "um erudito artigo sobre pedagogia moderna, pelo ilustrado senhor Dr. Sílvio Romero" (Gazeta de Notícias, 06/03/1885). Gentil de Faria, que conseguiu localizar apenas a segunda edição da obra na Biblioteca Nacional, afirmou, acerca do prefácio de Romero:

Sílvio Romero (1885, p. v), que nunca havia feito nenhuma menção ao autor do romance em sua consagrada História 
da literatura brasileira, escreveu oito páginas, datando-as, ao final, outubro de 1884 . O primeiro parágrafo diz: 'O Sr. professor Carlos Jansen, a quem as letras e a pedagogia brasileira já tanto devem, acaba de traduzir o celebrado romance Robinson Crusoé, de Daniel de Foe (sic). O livro foi pelo tradutor adaptado ao nosso meio social, segundo o plano de F. Hoffmann'. Depois de apontar os defeitos do ensino da leitura no seu tempo de escola primária, o crítico, que sempre manifestava má vontade para as traduções, finaliza o texto, elogiando o trabalho que prefaciou (ibidem, p.xii): 'O Robinson Crusoe, redigido para a mocidade brasileira, é um presente magnífico, um mimo que vai encantar, instruindo os nossos filhos; e os vai instruir sem afetações, sem lamúrias e pieguices nocivas'. (FARIA, 2008, p. 40-41).

Este último fragmento do prefácio, reproduzido por Faria, costumava constar nos anúncios da Laemmert na imprensa. Os prefácios de Machado de Assis e Sílvio Romero tinham, assim, uma função promocional.

Leonardo Arroyo (1990) foi provavelmente o primeiro a citar carta de Jansen a Rui Barbosa pedindo-lhe um texto de apresentação para As viagens de Gulliver, testemunho da precariedade das condições de trabalho dos tradutores no fim do século XIX. Na carta, Jansen afirma: "Bem sabe que o editor mal paga o trabalho; mas um operário como eu aspira a mais alguma coisa do que ao rendimento material" (BARBOSA, 1955, p. 249-250), e lamenta que seus opúsculos científicos, embora adotados pelo Governo, jamais foram vendidos.

Embora o pedido de Jansen fosse motivado pelo desejo de promover seu livro, Rui Barbosa redigiu um prefácio de natureza bem diversa daqueles de Assis e Romero: um ensaio erudito de 68 páginas sobre a vida e a obra de Swift. Datado de dezembro de 1887, o pomposo texto destoa da tradução de Jansen. Barbosa preocupa-se em exaltar a imagem de Swift contra a crítica, pouca atenção dando ao trabalho de Jansen: 
A infância e o povo ainda não encontraram leitura mais ao seu sabor. A fábula engenhosa, que os teoristas políticos circunspectantes inscrevem na classe das Utopias de organização social, é, ao mesmo tempo, excetuados certos lances, o livro mais aprazível que já se escreveu para crianças. Bem fez, portanto, o incansável adaptador deste livro à nossa língua em não se deter com as impressões pessimistas de Saint-Victor e Taine. Acredito que este novo trabalho vem juntar mais um título relevante aos que já o constituem benfeitor da mocidade brasileira. (BARBOSA, 1955, p. 309310). O itálico é uma referência a L. Stephen, em Swift).

Já o prefácio de Ferreira de Araujo a Dom Quixote retoma o perfil promocional dos dois primeiros, e busca ainda justificar a adaptação radical operada por Jansen:

Presta um bom serviço a casa Laemmert \& C., vulgarizando a obra prima da literatura espanhola. [...]

Aparando-lhe as asperezas e vertendo-o para o português com apurado gosto literário e a competência de que já tem dado provas, o Sr. Carlos Jansen presta um bom serviço à mocidade, dando-lhe a conhecer uma daquelas raras obras do engenho humano que tem o condão de agradar a todas as idades. Mais tarde, estes mesmos leitores irão ver no original, já sem a folha de parreira das conveniências, a única face que lhes fica por ora vedada do talento de Cervantes $[\ldots] .^{15}$

Ferreira de Araujo expõe a versão de Jansen como a porta de entrada a partir da qual os jovens leitores acessarão, posteriormente, o romance de Cervantes na íntegra. Tal posição rendeu-lhe crítica feroz por parte do jornalista Valentim Magalhães, condenando a reescrita de "obras primas do engenho humano universal", entre as quais o "imorredouro romance" Dom Quixote: "Com que direito um escritor - embora de reconhecidos méritos literários como o Sr. 
Carlos Jansen - se faz redator de uma obra concluída, consagrada pelos séculos ou, apenas, pelos anos?" (MAGALHÃES, 1886a, p.1). Magalhães nega que textos de grandes escritores possam ser reescritos (ou redigidos) para adequá-los a deteminada moral:

O ilustre prefaciador achará talvez isso "um bom serviço à mocidade"; eu acho-o um detestável desserviço feito às letras e principalmente à mocidade. Se esta precisa de livros cândidos, não falta onde escolher; e quando falte - escrevam-se especialmente para aquele fim. (1886a, p.1).

A posição de Magalhães repousa sobre o ideal romântico do escritor enquanto gênio intocável. Redigir o Dom Quixote seria profanação:

Uma obra literária ou artística é um todo, uma coisa concluída, definitiva, imodificável, sagrada. [...] São sempre condenáveis estas mutilações, que reduzem as grandes obras do espírito humano a eunucos da literatura e da arte. [...] Se Cervantes quisesse um D. Quixote inocentinho, próprio para regalo das loiras crianças, tê-lo-ia feito. [...] Portanto, "D. Quixote", redigido, com folha de parreira, sem pimenta, - não é D. Quixote, não é nada. (1886a, p.1).

Magalhães conclui sua crítica sugerindo que Jansen escreva "um romance interessante e inócuo, próprio para ser lido, com curiosidade e sem risco, pelas crianças" (1886a, p.1).

Dois dias após esse artigo, Magalhães escreve outro, intitulado Mau procurador, a fim de refutar réplica do jornalista e crítico literário Lulú Senior que, mediante procuração, manifestou-se em defesa de Ferreira de Araujo ${ }^{16}$. Magalhães aproveita a tréplica para reforçar suas divergências com o "Dr. Araujo quanto ao direito que se possa arrogar seja quem for de redigir obra alheia, sem ser 
ouvido nem consultado o respectivo autor" (1886b, p.1) e incluir as "damas pudibundas" no escopo moralizador das adaptações. Reitera ainda sua posição quanto à diferença entre adaptações para o teatro, aceitáveis, e a reescrita em livros, inadmissível.

$\mathrm{O}$ ataque de Magalhães - que curiosamente não tinha como alvo Carlos Jansen, mas seu prefaciador, Ferreira de Araujo - rendeu ainda outros embates nas páginas do Diário de Notícias. Na coluna De palanque, Artur Azevedo posiciona-se, ao lado de Valentim Magalhães, contra Araujo. Oculto sob o pseudônimo de Eloi, o Heroi, Azevedo despreza a capacidade infantil de absorver "grandes homens" e qualifica a adaptação de clássicos para crianças como "dinamização homeopática":

O D. Quixote saiu das mãos do Sr. Carlos Jansen ainda mais mutilado do que o famoso Cavalheiro da Triste Figura quando voltava dos seus inauditos combates. [...]

Cervantes, Boccacio, Rabelais, Shakespeare e outros sublimes pornográficos foram grandes homens que só escreveram para homens grandes. Não há vantagem alguma em metê-los nas mãos das crianças, pois para estas outros autores existem, que não precisam de poda. Na idade em que se compreende o D. Quixote, na idade em que ele deve ser lido, não há pornografias que pervertam o espírito, não há pudor que lhes não resista. (AZEVEDO, 1886, p.1).

Assim como Magalhães, Azevedo admite a supressão de partes de um texto apenas em peças teatrais, "para serem representadas em épocas menos escrupulosas que as nossas para espectadores menos pudicos que nós; mas no livro deve ser conservado tal qual saiu do cérebro do autor". (AZEVEDO, 1886, p.1).

É interessante contrastar a posição de Magalhães e Azevedo com comentário em coluna não assinada na Gazeta de Notícias de 25/02/1885 acerca da tradução de Robinson Crusoe: 
No seu trabalho, alguns dos episódios característicos do original desapareceram, mas nem por isso a feição geral do livro foi profundamente alterada. Colhe-se até uma vantagem, que é dar maior vida e movimento à narrativa, e desprezar muitas das reflexões e homelias que o pululam no original. (ano XI, n. 57, capa). ${ }^{17}$

É antiga a polarização entre os defensores das traduções fiéis, ou integrais, e aqueles que aceitam a adaptação, em seus diferentes graus, como forma legítima de aproximar o texto do leitor alvo. Considerar um ou outro modelo como superior, aceitável ou adequado depende em grande parte da função que a tradução assume em determinado tempo ou cultura. O embate entre Magalhães e Azevedo, de um lado, e Araujo e Senior, do outro, repousa sobre noções explícitas e implícitas quanto à função da tradução. Magalhães, ao questionar o direito de Jansen de mutilar a obra de Cervantes, apoia-se em uma concepção servil da tradução, cujos direitos são limitados pela reverência ao original. Araujo, por sua vez, defende o projeto pedagógico de Jansen e os benefícios de se produzir um texto acessível e apropriado (conforme a moral da época) aos jovens leitores, numa abordagem que privilegia o polo receptor do texto.

Nenhum dos outros livros ou prefaciadores de Jansen sofreu ataque semelhante. Uma hipótese para tanto, no caso de Machado de Assis e Rui Barbosa, é a elevada reputação que esses escritores possuiam, tornando-os imunes a ataques. Ao introduzir as Mil $e$ uma Noites, Assis deixa claro que o livro foi adaptado "adotando o plano do educacionista alemão Franz Hoffmann" e que não se trata de uma tradução integral, afirmando sobre os contos: "Os melhores daqueles, ou alguns dos melhores, estão encerrados, neste livro do Sr. Carlos Jansen” (ASSIS, 1994, s/p). É provável, porém, que o nome de Miguel de Cervantes pese ainda mais que os dos prefaciadores brasileiros. Todos os livros da biblioteca de Jansen têm a indicação de Hoffmann como inspirador de seus procedimentos de redação, e em todos está claro que se trata de obra adaptada, 
não de uma tradução integral. Por que, então, apenas Dom Quixote suscitou tais críticas?

Pascale Casanova explica que os clássicos se tornam unidade de medida a partir dos quais serão julgados aqueles que doravante desejarem disputar um lugar na República Mundial das Letras:

Os nomes de Shakespeare, Dante ou Cervantes resumem ao mesmo tempo a grandeza de um passado literário nacional, a legitimidade histórica e literária conferida por tais nomes a uma literatura nacional e o reconhecimento universal portanto enobrecedor e conforme à ideologia não nacionalista da literatura - de sua grandeza. (2002, p. 29).

O "pecado" cometido por Jansen parece residir neste ponto: um professor radicado no Brasil, país ainda sem tradição literária própria, verte para o português brasileiro, tomando para isso todas as licenças possíveis, um clássico como Cervantes. E não apenas isso: entrega-o nas mãos de um público que, conforme a visão adulta, tem limitadas habilidades de leitura.

Algumas adaptações e coletâneas adquiriram, com o tempo, o estatuto de obra original. É o caso dos contos reunidos pelos irmãos Grimm, histórias transmitidas oralmente que foram documentadas e petrificadas na forma escrita, ou a versão de Antoine Galland das 1001 Noites, que se tornou texto de partida para a difusão da obra pelo mundo:

A princípio foi olhado com muita desconfiança e desdém pelos orientalistas, não só por duvidarem da fidelidade de Galland a textos originais, mas também pela licensiosidade de seu conteúdo e vulgaridade de estilo, inteiramente oposto à pomposa retórica árabe. Só em princípios de século XIX, muito mais por interesses filológicos do que literários, a crítica erudita passou a se interessar pela coletânea. Nesse momento, ela já se difundira por todo o mundo ocidental 
através das várias literaturas populares, e diversos de seus episódios passaram a ser divulgados como Literatura Infantil. (COELHO, 2010, p. 15).

Oittinen vê a adaptação não apenas como algo intrínseco a toda tradução (em maior ou menor grau), mas também como um fenômeno positivo para o texto de partida, que sobrevive em virtude das reescritas que dele são feitas. A autora explica, contudo, que a adaptação deve ser transparente:

Os leitores têm todo o direito de conhecer a 'história' de cada livro que estão lendo: se o livro é a primeira, segunda ou terceira versão; as datas de publicação; os nomes de todas as pessoas envolvidas (tradutor, ilustrador); e os meios e razões do tradutor, talvez na forma de prefácio ou posfácio. $(2002$, p.80).

Os livros traduzidos por Jansen traziam sempre a indicação redigido por, equivalente hoje a reescrito, adaptado ou recontado por, que confere transparência à origem do texto. O tradutor é tão visível que assume as vezes de autor, sendo o nome deste último citado quase que como uma inspiração. Acerca de Robinson Crusoe, Gentil de Faria escreve:

Jansen, coerente com o propósito de adaptar a obra para jovens, não apenas a dividiu em capítulos, como acrescentou um breve sumário do conteúdo de cada um. Isso facilitou grandemente a tarefa de leitura da obra pelos seus jovens alunos. Todos eles sabiam que estavam lendo uma adaptação e não uma tradução integral. (2008, p. 41, grifos nossos). 
Os prefácios e os anúncios da Laemmert também são testemunho da visibilidade do projeto de adaptação das obras para o público jovem, conforme vimos anteriormente.

Yves Gambier (1992), examinando a adaptação sob um ponto de vista comunicacional, elenca três sentidos (não exaustivos) que ela pode carregar. O primeiro consiste em fazer acréscimos ou omissões com a justificativa de conservar o efeito do texto original, prática focada na língua de chegada, que elimina a diferença e faz o texto traduzido parecer um original. $O$ segundo diz respeito a construir um novo original a partir de outro, composto ou não pelo mesmo sistema de signos. São os casos de tradução intersemiótica (conforme Jakobson) e a reescrita das fábulas de Esopo e Fedro por La Fontaine: "É a este sentido (b) que se aplica exclusivamente a denominação de adaptador" 18 (GAMBIER, 1992, p. 422). O terceiro sentido que a adaptação pode carregar é a transfomação de um texto com vista a um leitorado específico, como o infanto-juvenil. Na prática de Jansen predomina esta última definição, embora haja procedimentos das demais mescladas. Gambier a chama de adaptação-reescritura:

\begin{abstract}
Essa adaptação-reescritura (com substituição de palavras, escolhas de genéricos, condensação de sintagmas, paráfrases, contração de parágrafos, modificação de tempos, manipulação de proposições complexas, novos agenciamentos temáticos, encurtamento de frases...) é uma forma de tradução intralingual (Jakobson, 1967), não sem analogia com a fala do adulto palavreando com uma criança peque$n a$, a fala de um nativo dirigindo-se a um não-nativo (migrante, público de estrangeiros...), não sem analogia com a vulgarização científica, a propaganda política, as campanhas publicitárias... supostamente dirigidas a públicos específicos. ${ }^{19}$ (GAMBIER, 1992, p. 423, grifos nossos).
\end{abstract}

Com base nessa descrição e nos relatos na imprensa brasileira em fins do século XIX, podemos traçar um paralelo entre a vul- 
garização científica, empreendida por Jansen em seus opúsculos, e a vulgarização literária que ele efetuou na composição de sua biblioteca juvenil. Conforme o dicionário Aulete, o termo significa "ação ou resultado de vulgarizar(-se), tornar(-se) comum, bem difundido, popularizado (vulgarização da cultura; vulgarização da ciência); disseminação". ${ }^{20}$

Não se pode discutir a legitimidade do projeto tradutório de Jansen apoiando-se apenas em argumentos relativos aos direitos do autor, do tradutor ou do leitor, à sacralidade da obra ou às funções da tradução. É imprescindível levar-se em conta o sentido da tradução: se centro-centro, periferia-periferia, centro-periferia ou periferia-centro. Em outras palavras: é necessário avaliar se a empreitada domesticadora, vulgarizadora e moralizadora parte de uma potência literária e linguística disposta a anexar e anular o estrangeiro ou se, ao contrário, parte de um subúrbio buscando de alguma forma construir um repertório literário próprio. As versões de Jansen, como vimos, estão entre os primeiros textos em português brasileiro. Elas habitam um sistema literário jovem, sem tradição ou herança; e se o sistema literário do Brasil colônia é jovem, tanto mais seu subsistema literário infantil.

Observando a situação sob um ponto de vista sistêmico, as traduções de Jansen não operam apenas no sentido interlinguístico, mas trazem o texto de um sistema - o da literatura adulta, especialmente no caso de Cervantes - para outro - o da literatura infantil. Neste caso, ele tende a submeter-se a restrições típicas desse novo sistema. (SHAVIT, 1986).

A prática de adaptar textos da literatura adulta para crianças e adolescentes está na própria gênese da literatura infantil no ocidente. Somente após esse estágio de empréstimo é que se começam a escrever livros especificamente para crianças. Algumas dessas obras permanecem vivas em suas versões adaptadas, enquanto os textos integrais passaram a compor o cânone da literatura adulta, porém mais como monumentos históricos que como obras ativas (SHAVIT, 1986).

Jansen não fez nada de novo ao realizar essa dupla tradução - entre línguas e entre sistemas. Seguiu o mesmo caminho que 
haviam seguido as literaturas europeias no processo de segmentação de público, iniciado no século XVII com a disseminação das escolas e firmado no século XVIII (1986). Foi, porém, o primeiro a fazê-lo no Brasil, produzindo por meio da tradução as primeiras obras de literatura dirigidas aos jovens no país. Suas versões seriam posteriormente revistas por Monteiro Lobato - autor que operaria uma revolução estética na literatura infantil - por não considerá-las suficientemente abrasileiradas.

Percebe-se, portanto, a importância de Carlos Jansen na história da literatura infantil brasileira, tendo sido pivô na gênese desse segmento. Natural que tenha sofrido ataques no percurso, pois partiu de três sistemas periféricos no polissistema literário: o sistema dos tradutores, em relação àquele dos escritores; o sistema brasileiro, em relação ao europeu; e o sistema infantil, em relação ao adulto. Por essa razão Jansen emprega, em seu projeto, todos os recursos possíveis para legitimar-se: sua reputação enquanto professor do Colégio Pedro II, seus colaboradores na imprensa e, especialmente, seus prefaciadores. E sai-se bem na empreitada, deixando de herança as cinco primeiras traduções literárias de clássicos para jovens em português brasileiro.

\section{Notas}

1. Há divergências entre os biógrafos quanto à data de nascimento de Jansen, apontada por alguns como o ano de 1823 (HOHLFELDT, 2003).

2. HOHLFELDT (2003). JANSEN, Carlos. O patuá, novela gauchesca. Porto Alegre: Gabinete de Pesquisa de História do Rio Grande do Sul/IFCH/UFRS, 1974. Estudo crítico e biográfico por Dante de Laytano. BECKER, Klaus. Imprensa em língua alemã (1852-1889), in Enciclopédia Rio-Grandense. Porto Alegre, 1956. GRÜTZMANN, Imgart; DREHER, Martin Norberto; FELDENS, 
Jorge Augusto. Imigração Alemã no Rio Grande do Sul - recortes. Okos, Unisino: São Leopoldo, 2008.

3. Disponível em: http://memoria.bn.br/DocReader/docreader. aspx $? \mathrm{bib}=222402 \&$ PagFis $=8841$. Acesso em 07/08/2015.

4. Diário de Notícias, 29/09/1888, ano IV, n. 1204. Disponível em: http://memoria.bn.br/DocReader/ DocReader.aspx?bib $=369365 \&$ PagFis $=4885$. Acesso em 11/08/2015.

5. Disponível em: http://memoria.bn.br/DocReader/DocReader. aspx $? \mathrm{bib}=313394 \mathrm{~b} \& \mathrm{PagFis}=58309$. Acesso em 10/08/2015.

6. Arroyo (1990), Lajolo e Zilberman (2007) e Hallewell (2005) apontam 1901 como ano de publicação de Dom Quixote. O livro, porém, foi lançado em 1886, conforme testemunham anúncio da Laemmert na Gazeta de Notícias de 26/12/1886 (ano XII, n. 360, p. 4) e diversos outros publicados na imprensa nos anos subsequentes. Apenas as Aventuras pasmosas do celebérrimo Barão de Münchhausen foram publicadas postumamente, dois anos após a morte de Jansen.

7. Disponível em: http://memoria.bn.br/DocReader/docreader.aspx?bib $=1037$ 30_02\&PagFis $=14687$. Acesso em 10/08/2015.

8. Disponível em: http://memoria.bn.br/DocReader/docreader. aspx?bib $=226688 \&$ PagFis $=16822$. Acesso em: $12 / 08 / 2015$.

9. Disponível em: http://memoria.bn.br/DocReader/DocReader. aspx?bib=103730_02\&PagFis=4694. Acesso em 11/08/2015.

10. Disponível em: http://memoria.bn.br/DocReader/docreader. aspx?bib=103730_02\&PagFis $=8287$. Acesso em 11/08/2015.

11. Disponível em: http://memoria.bn.br/DocReader/docreader. aspx?bib=103730_02\&PagFis $=8324$. Acesso em 11/08/2015.

12. Disponível em: http://memoria.bn.br/DocReader/docreader.aspx?bib $=1037$ 30_02\&PagFis $=11394$. Acesso em 11/08/2015. 
13. Disponível em: http://memoria.bn.br/DocReader/docreader. aspx? $b i b=225029 \&$ PagFis $=1772$. Acesso em 12/08/2015.

14. Disponível online:http://machado.mec.gov.br/images/stories/pdf/critica/ mact30.pdf)

15. O fragmento é reproduzido no artigo A Redação do D. Quixote, assinado por Valentim Magalhães, no Diário de Notícias de 28/12/1886. (MAGALHÃES, 1886).

16. Em busca exaustiva nos acervos da hemeroteca, não conseguimos localizar a réplica de Senior.

17. Disponível em: http://memoria.bn.br/DocReader/docreader. aspx?bib $=103730 \_02 \&$ PagFis $=8287$. Acesso em 13/08/2015.

18. "C'est à ce sens (b) que s'applique exclusivement la dénomination d'adaptateur". Tradução minha.

19. "Cette adaptation-réecriture (avec substitution de mots, choix génériques, condensation de syntagmes, paraphrasage, contraction de paragraphes, modification de temps, manipulation de propositions complexes, nouvel agencement thématique, raccourcissement de phrases...) est une forme de traduction intralinguale (Jakobson 1967), non sans analogie avec le parler d'un adulte bavardant avec un petit enfant, le parler d'un natif s'adressant à un non-natif (migrant, public d'étrangers...), non sans analogie avec la vulgarisation scientifique, la propagande politique, les campagnes publicitaires... supposées viser des publics précis". Tradução minha.

20. Disponível em: http://www.aulete.com.br/vulgariza\%C3\%A7\%C3\%A3o\#ix zz3cB19M7aq. Acesso em 17/08/2015. 


\section{Referências}

ARROYO, Leonardo. Literatura infantil brasileira. São Paulo: Melhoramentos, 1990. $10^{\mathrm{a}}$ ed.

ASSIS, Machado de. Obra Completa de Machado de Assis, Rio de Janeiro: Nova Aguilar, vol. III, 1994. Texto publicado como prefácio a Contos seletos das mil e uma noites, Rio de Janeiro, Laemmert \& C., s/d. Republicada na Revista do Brasil, junho de 1939. Disponível em: http://machado.mec.gov.br/images/stories/ pdf/critica/mact30.pdf. Acesso em 17/08/2015.

AZEVEDO, Arthur. De palanque. Diário de Notícias, 31/12/1886, n. 571, p. 1. Disponível em: http://memoria.bn.br/DocReader/docreader. aspx?bib $=369365 \&$ PagFis $=2327$. Acesso em 13/08/2015

BARBOSA, Rui. Obras completas de Rui Barbosa. Vol. XIV 1887 Tomo I. Rio de Janeiro: Ministério da Educação e Cultura, 1955.

CASANOVA, Pascale. A República Mundial das Letras. São Paulo: Estação Liberdade, 2002. Trad. Marina Appenzeller.

COELHO, Nelly Novaes. Panorama histórico da literatura infantil/juvenil: das origens indo-europeias aos Brasil contemporâneo. Barueri: Manole, 2010. $5^{\text {a }}$ ed.

FARIA, Gentil de. As primeiras adaptações de Robinson Crusoe no Brasil. in Revista Brasileira de Literatura Comparada, n. 13. São Paulo: Abralic, 2008.

GAMBIER, Yves. Adaptation: une ambiguïté à interroger. Meta: journal des traducteurs, vol. 37, n. 3, 1992, p. 421-425. Disponível em: http://id.erudit.org/ iderudit/002802ar. Acesso em: 06/11/2014.

HOHLFELDT, Antônio. Deus escreve direito por linhas tortas: o romance-folhetim dos jornais de Porto Alegre entre 1850 e 1900. EDIPUCRS: Porto Alegre, 2003. 
JÚNIOR, Araripe. Viagens de Gulliver. A Semana, ano 4, v. 4, n. 167-168, p. 73-74. Rio de Janeiro, 08/04/1888. Disponível em: http://memoria.bn.br/DocReader $/$ docreader .aspx? bib $=383422 \&$ PagFis $=1323$. Acesso em 07/08/2015.

LAJOLO, Marisa; ZILBERMAN, Regina. Literatura infantil brasileira: História e Histórias. $6^{\text {a }}$ Ed. São Paulo: Ática, 2007.

MAGAlHÃES, Valentim. A Redação do D. Quixote. Diário de Notícias, ano II, n. 568 p. 1. Rio de Janeiro, 28/12/1886a. Disponível em: http://memoria. bn.br/DocReader/docreader. aspx $? \mathrm{bib}=369365 \& \mathrm{PagFis}=2315$. Acesso em 13/08/2015.

. Mau procurador, Diário de Notícias, ano II, n. 570 p. 1. Rio de Janeiro, 30/12/1886b. Disponível em: http://memoria.bn.br/DocReader/docreader.aspx? $\mathrm{bib}=369365 \&$ PagFis $=2323$. Acesso em 13/08/2015.

MONTELLO, Josué. Na casa dos quarenta, São Paulo: Martins, 1967

OITTINEN, Riitta. Translating for children. New York: Garland Publishing, Inc., 2002.

ROSA, Gama. In-folios e folhetos. Gazeta da Tarde, Ano III, n. 277, p. 2. Rio de Janeiro, 04/12/1882. Disponível em: http://memoria.bn.br/DocReader/DocReader.aspx?bib=226688\& PagFis $=2480$. Acesso em 18/08/2015.

SHAVIT, Zohar. Poetics of children's literature. Atenas e Londres: The University of Georgia Press, 1986.

TÁVORA, Franklin. Notas bibliográficas: Geografia e Física, Geologia e Astronomia, opúsculos elementares de A. Geikie e N. Lockier, adaptados ao português por Carlos Jansen. Revista Brasileira, $1^{\circ}$ ano, Tomo IV, p. 357. Rio de Janeiro, 1880. Disponível em: http://memoria.bn.br/DocReader/DocReader. aspx $? \mathrm{bib}=139955 \&$ PagFis $=3740$. Acesso em 18/08/2015.

Recebido em: 29/08/2015

Aceito em: 10/10/2015 